\title{
Home Parenteral Nutrition in Patients with Advanced Cancer: a Systematic Review and Meta-analysis
}

\author{
Francis J. O’Hanlon, ${ }^{1}$ Konstantinos C. Fragkos, ${ }^{1}$ Lucia Fini, ${ }^{2}$ Pinal S. Patel, ${ }^{1}$ Shameer J. \\ Mehta, ${ }^{1}$ Farooq Rahman, ${ }^{1}$ Simona Di Caro ${ }^{1}$ \\ ${ }^{1}$ Intestinal Failure Service, Department of Gastroenterology, University College London \\ Hospitals NHS Foundation Trust, United Kingdom \\ ${ }^{2}$ Department of Internal Medicine, Gastroenterology and Digestive Endoscopy Unit, Busto \\ Arsizio Hospital, Busto Arsizio, Italy
}

Correspondence to:

Dr Simona Di Caro

Intestinal Failure Service, Department of Gastroenterology

University College London Hospitals NHS Foundation Trust

250 Euston Road, London NW1 2PG, United Kingdom

e-mail: simona.dicaro@nhs.net

Tel. +44 (0) 20344 79311, Fax: +44 (0) 2034479217

\section{ABSTRACT}

The use of home parenteral nutrition (HPN) in patients with incurable cancer remains controversial with significant variation worldwide. We aimed to systematically evaluate the literature from 1960 to 2018 examining the use of HPN in advanced cancer patients for all intestinal failure indications and assess the potential benefits/burdens of HPN in this cohort of patients. The primary end point was survival and secondary end points were quality of life and nutritional/performance status. Meta-analysis was performed with a random effects model, where suitable. Of 493 studies retrieved, 22 met the quality inclusion criteria. Studies were mainly conducted in Western countries (Italy, USA, Canada, Germany), including a total of 3564 patients (mean age 57.8 years). Mean duration for HPN was 5.0 months. Mean overall survival was 7.3 months. Patients with improved performance status survived for longer on HPN. Quality of life was sparsely reported though there was no observed negative impact of PN. HPN-related complications were reported in eight studies only and were mainly catheterrelated blood stream infections. In conclusion, HPN is used for several indications in advanced cancer, though there is significant heterogeneity of results. Disparities in geographical distribution of the studies may reflect variation in accessing HPN.

Keywords: advanced cancer, parenteral nutrition, performance status, systematic review 
O’Hanlon et al. 2

\section{INTRODUCTION}

Cancer is the second leading cause of death globally, with an estimated 18.1 million new cases, 9.6 million deaths in 2018 and a global economic cost of $\$ 1.16$ trillion per annum $(1,2)$. Advanced cancer is commonly defined as a tumour that has spread to other sites in the body that usually cannot be cured or controlled with treatment (3). Cancer disrupts intrinsic mechanisms for cellular growth and regeneration; as cancer progresses these effects may become notable through the development of symptoms such as weight loss, fatigue and diminished appetite which ultimately will be detrimental for nutritional status and lead to cachexia (4-6). Cachexia is a complex metabolic syndrome characterised by loss of muscle mass (sarcopenia), regardless of fat mass/loss and therefore represents a different metabolic process than simple starvation or body compositional changes related to age (7). Cachexia is observed in up to $80 \%$ of patients with gastrointestinal or head and neck cancers (8).

Intestinal failure is defined as the reduction of gut function below the minimum necessary for the absorption of macronutrients and/or water and electrolytes, such that intravenous supplementation is required to maintain health and/or growth $(9,10)$. Malignant mechanical bowel obstruction due to peritoneal metastases is the most common cause of intestinal failure in cancer patients, however, other indications may occur in clinical practice such as: dysmotility, peristaltic failure (ileus), fistula formation, high stoma output and reduced absorptive mucosal surface due to short or diseased bowel post-surgery or during/after chemotherapy or as a consequence of radiation enteropathy.

As treatments continue to evolve, patients are increasingly able to survive for longer with a cancer diagnosis. In turn, malnutrition impairs the body's ability to withstand anti-cancer therapies such as chemo/radiotherapy or surgery (11). In the context of malignant intestinal failure (in patients with cancer), current guidelines recommend that home parenteral nutrition (HPN) is indicated when expected survival is greater than 2-3 months; parenteral nutrition (PN) is expected to stabilise or improve performance status and / or quality of life; with the provision that the patient desires it $(10,12,13)$. Once a stable PN regimen has been started, a subset of patients may be able to continue receiving HPN. Although patients with cancer account for a significant and increasing proportion of patients receiving HPN within Europe $(14,15)$, the issue remains controversial and access to PN varies both nationally and internationally (16).

There are important clinical and ethical factors which must be carefully considered prior to starting HPN therapy: firstly, set up of therapy usually requires an inpatient admission for 2-3 weeks of biochemical monitoring and prescription adjustments. Subsequently the willingness and ability of a patient and/or their caregivers to receive frequent input from homecare companies for delivery of supplies, connection and disconnection of infusions at home (unless the patient and/or their caregivers are able to undergo suitable training) and regular outpatient review. HPN is an expensive treatment with costs approximately $€ 124$ (£106 at the time of writing) per patient per day (17). There is also a necessity for long-term central venous catheter placement with associated risks. It has been suggested that PN may potentially accelerate tumour growth (18), however, according to the European Society for Clinical Nutrition and Metabolism (ESPEN) there is no convincing evidence to support this (19).

The authors of a recent Cochrane review concluded that they were uncertain as to whether HPN conferred improvement in survival or quality of life and it was unclear about HPN's impact on adverse events in patients with malignant bowel obstruction (20). Whilst malignant bowel obstruction is the commonest indication for HPN in patients with advanced cancer, there are other significant indications which should not be overlooked (12). We speculate that this approach may omit potentially useful data from studies examining the role of HPN in such cases and hence aimed to systematically review the potential advantages/disadvantages of receiving HPN for all indications in patients with advanced cancer within the literature. 


\section{METHODS}

\section{Study Eligibility Criteria}

Inclusion criteria were any empirical study (full text paper) with quantitative data examining HPN in adult (over 16 years old) advanced cancer patients. There was a restriction to English language studies published up until December 2018. All indications for HPN were included in this review. Exclusion criteria included other study types (reviews, case reports, opinion articles, and letters to the editor), studies where patients did not have advanced cancer, or those where patients received inpatient parenteral nutrition only, and studies with children or adolescents.

\section{Search Strategy and Terms}

PRISMA guidelines for systematic reviews and meta-analyses were followed (21). Electronic database searches were conducted between 1 January 1960 up until 31 December 2018 in Google Scholar, PubMed/Medline, Scopus, and EMBASE. The keywords used for searching were: cancer, advanced cancer, palliative, terminal cancer, parenteral, nutrition, parenteral nutrition, artificial nutrition, intravenous nutrition, oncology, non-surgical oncology, survival, quality of life, performance status; and combinations of these terms. Selected article references and relevant journals (Clinical Nutrition, Nutrition, Journal of Parenteral and Enteral Nutrition) were also hand searched for any additional relevant studies. Duplicates were removed.

\section{Study Selection, Data Extraction and Quality Assessment}

The abstracts of the retrieved studies were evaluated in terms of inclusion criteria. The full text was consulted when the abstract was not adequate to warrant inclusion. The primary outcome was to assess the effect of HPN on overall survival. Secondary outcomes included: quality of life, nutritional status, and any relevant indices i.e. haematological markers, biochemical markers, performance status or patient demographics, which may aid future clinical prognostication. We extracted the following data from the included studies: author, year of publication, study aim, main results, type of analysis, type of subjects, country, continent, sample size, mean age, female percentage, survival, Karnofsky Performance Status (KPS), body mass index (BMI), percentage of weight loss, HPN duration, and quality of life measures and results. The definitions of the scores frequently used for performance status are presented in Table 1. The quality of studies (risk of bias) was assessed with elements from Cochrane Collaboration's tool (22) and the Research Triangle Institute Item Bank for Observational Studies (23), which assess selection, attrition, detection and confounding biases.

---Table 1 here---

\section{Statistical Analysis}

Quantitative analysis was performed with R 3.5.1. A random effects model was used to produce a pooled estimate of means and standard deviations where possible. When medians and interquartile or minimum-maximum ranges were reported, these were converted to means and standard deviations with standard formulas $(30,31)$. Heterogeneity between studies was quantified using the $\mathrm{I}^{2}$ statistic ( $\mathrm{p} \leq 0.10$ for significance) (32), with values over $50 \%$ indicating considerable heterogeneity (33-36). 


\section{RESULTS}

\section{Selection of relevant studies}

Two independent reviewers screened 493 article abstracts and selected relevant studies for inclusion to be read in full. All articles chosen for final inclusion in the review were 95\% concordant between the two reviewers with a third reviewer to settle any discrepancies. Twenty articles met inclusion criteria (Figure 1): 13 studies were conducted retrospectively and 9 were prospective; 15 studies were from a single centre, while 8 were multi-centre (Table 2). Only one study was designed as a randomised control trial (37). Another study compared patients who were started on home enteral nutrition to those started on HPN (38), however did not include a control group, whilst a further prospective study compared patients on HPN with advanced cancer to those with non-cancer diagnoses (39). Many groups noted the lack of control data and randomisation as a limitation due to the unethical nature of randomising or withholding nutritional support.

---Figure 1 here---

---Table 2 here---

\section{Characteristics of key studies}

The studies were conducted in various countries worldwide: Europe, North America, and East Asia: Italy (38, 40, 41, 44, 55, 57), Israel (39, 50), Germany (48, 53), France (54), Sweden (37), UK (16), USA $(43,52,56)$, Canada (42, 47), China (45), and Taiwan (46). One study included pan-European data (51). A total of 3564 patients (55.1\% females) with advanced cancer on HPN were included in the 22 studies. Not all studies reported gender distributions $(38,40,49,53)$. Mean age was 57.8 years. Two studies did not disclose age demographic data of their populations $(39,55)$. A wide range of cancer sub-types were included, though most studies focused on solid tumours of the GI tract (37.4\%), followed by gynaecological (ovarian, endometrial, cervical) (6.8\%) and 'others' (6.3\%). The primary diagnoses of $1240(35 \%)$ patients were unclear or not known. Within the limitations of mostly retrospective small-sized samples, the main bias was due to lack of adjustment of confounding factors (41\%) (Figure 2). In terms of reported nutritional and prognostic parameters, meta-analyses were performed for BMI, percentage of weight loss and KPS. From meta-analyses, the mean for BMI was at the lower end of normal at $20.9 \mathrm{~kg} / \mathrm{m}^{2}\left(95 \%\right.$ CI 20.2-21.6, range 19.7-24.2. $\left.\mathrm{I}^{2}=94 \%\right)(16,40,42$, $44,48,50,51,53,54,56$ ), weight loss when starting HPN was high at $16.3 \%$ (95\% CI 7.325.3, range 9.5-31.5, $\left.\mathrm{I}^{2}=100 \%\right)(16,41,42,44,51,52,54,55)$, while mean KPS score was 56 (95\% CI 49-62, range 35-70, $\left.\mathrm{I}^{2}=99 \%\right)(16,38,40-42,44,47,51,52,55)$ (Figure 3A-C).

---Figure 2 here---

Of the 22 selected studies 3564 patients with advanced cancer were included. HPN was most commonly indicated for intestinal failure secondary to malignant bowel obstruction. Although complete data was not available for all studies $(40,48,52,53)$, we found that $1196(34 \%)$ patients with intestinal failure received HPN for other reasons (malabsorption, intractable nausea, fistulae, short bowel syndrome etc.). At least 766 (21\%) patients received HPN for reasons other than intestinal failure, most commonly cachexia / cancer or treatment-related malnutrition $(16,37,38,41,48,54,56)$. A number of studies did not provide complete information on HPN indication $(39,51-53,57)$. 


\section{Survival}

Nineteen studies primarily examined the effect of HPN on patient survival (16, 37-47, 49-51, 54-57). Sixteen studies reported median survivals ranging between 1.5 and 10.4 months, with corresponding mean survivals ranging between 2.3 and 21.8 months $(16,39-47,49-52,55,57)$. The meta-analytic mean survival was 7.3 months $\left(95 \%\right.$ CI 6.3-7.8, $\left.\mathrm{I}^{2}=99 \%\right)$ (Figure 3D). Fourteen studies gave more detailed data regarding survival $(16,37-39,41,43,45,46,50-52$, $55,57)$ at different time points: with mean 3 -month survival of $68 \%(16,37,38,41,51,55$, $57), 6$-month mean survival of $40 \%(16,37,39,51,52,55)$, and mean 1-year survival of $25 \%$ $(37,39,41,43,45,46,50,52,55)$. Nine studies reported median duration of HPN ranging between 3.0 and 5.0 months, with corresponding means ranging between 2.3 and 21.8 months $(16,38,41-43,52,53,55,56)$. The meta-analytic mean for duration of HPN was 5.0 months (95\% CI 3.9-6.0, $\mathrm{I}^{2}=98 \%$ ) (Figure 3E).

Minimum life expectancy for starting PN was variable, with some studies starting HPN in 'any' case which was deemed clinically appropriate $(16,40,41,44,50,54)$, others specified 6 weeks (38); 2-3 months $(41,42,52,55,57)$ - as per current ESPEN guidelines $(12,13,58)$; or 'a few' months $(45-47,49)$. One study set minimum life expectancy of six months for cohort recruitment (37).

Lundholm et al. (37) carried out a randomised control study of 309 cachectic patients with cancer. All patients were given a baseline regimen of an oral cyclooxygenase inhibitor (indomethacin) and erythropoietin injections, if required, to improve anaemia and reduce the systemic inflammatory response. The randomised treatment group $(n=139)$ were given additional nutritional support (around 50\% with HPN) which showed a significant survival benefit of treatment- over control- group $(\mathrm{p}<0.001)$. Twenty nine patients on HPN survived beyond 7 months and 16 survived beyond 10 months. Patients who were nutritionally supported were more likely to re-establish oral feeding than the control group (p 0.03).

Two studies specifically examined whether HPN led to survival beyond one year in patients with a range of PN indications including malignant bowel obstruction, short bowel syndrome, malabsorption, GI fistula, dysmotility and vomiting. Hoda et al. (43) conducted a retrospective analysis of 52 patients with advanced metastatic cancer between 1979 and 1999. Median time from initiation of PN to death was 5 months (range 1-154). Sixteen patients survived over one year. From these findings, they suggested a possible role for HPN in patients with advanced cancer. Fan et al. (45) followed 115 adult patients with malignant gastrointestinal obstruction, with median survival of 6.5 months. Eleven patients survived over one year and two patients were alive almost four years later. Two studies did not disclose age demographic data of their populations $(39,55)$.

Wang et al. (46) conducted a retrospective analysis of 20 patients with incurable cancer as a primary diagnosis who required HPN for at least 30 days. Indications for HPN included malignant bowel obstruction, malnutrition, short bowel syndrome and post-operative complications such as fistulation. Median survival in cancer patients was 4 months (range 136 ), with four patients surviving longer than one year. The authors concluded that HPN allowed $20 \%$ of patients with incurable cancer to survive over one year, who would otherwise have died from malnutrition without HPN support, and like others argued that there is a role for HPN in such patients.

Chermesh et al. (50) prospectively followed 28 patients with malignant bowel obstruction. They compared this group with 40 patients referred for HPN with non-malignant processes. In cancer patients only, the median survival was 4.6 months. Patients with KPS $\geq 50$ had significantly improved survival than patients with a score $<50$ (211 versus 62 days; $p=0.01)$ for cancer patients. 23 patients $(82 \%)$ survived over one month, however, 6- and 12-month survival in this cohort was only $1 \%$ ( 3 and 2 patients respectively). The authors concluded that 
HPN should be considered for the alleviation of symptoms of starvation in patients with advanced disease, whose prognosis is longer than 'a few days'.

Cotogni et al. (55), prospectively followed-up a cohort with stage III-IV disease and baseline KPS scores over 50, with $67 \%$ survival at 3 months and $34 \%$ at 6 months. In a separate cohort, Cotogni et al. (57) reported $43.1 \%$ survival $\geq 1$ year in patients with stage III-IV malignancies (baseline KPS was $\geq 70$ in $66.2 \%$ of patients) receiving HPN and anti-cancer treatments.

---Figure 3 here---

\section{Predictors of survival}

A number of studies examined potential prognostic factors which could predict survival in patients with advanced malignancy receiving HPN. Santarpia et al. (44) recruited 152 patients with irreversible malignant bowel obstruction. Selected anthropometric measurements, haematological markers, biochemical markers and clinical variables were monitored at baseline and at subsequent 30 day intervals. They found that higher KPS over 40 and cholinesterase were the only significant predictors of survival $(p<0.001$ and $p=0.011)$ in their cohort.

Soo and Gramlich (47) analysed a retrospective cohort of 38 patients with non-treatable cancer and intestinal failure due to malignancy. Mean survival was 5.4 months (range 0.25-33). They showed higher KPS $(>50)$ correlated with improved survival (median 6 months) versus KPS $\leq$ 50 (median 3 months) $(\mathrm{p}=0.01)$. The authors argued that the survival benefit of HPN became apparent if initiated when patients had a higher level of function (KPS > 50).

This finding is supported also by Keane et al. (16). Prognostic indicators were examined in 107 patients, most of whom had metastatic disease and had undergone active oncological therapies before and / or alongside HPN (90.4\%). Overall mean survival was 1 month and median survival was 3.2 months from discharge date (of note, PN was usually started 2-3 weeks prior to this). After multivariate analysis, only higher KPS and lower Glasgow Prognostic Score emerged as significant predictors of survival (KPS $\geq 50$ was 4 months versus 1 month for KPS $<50 ; \mathrm{p}=0.05)$. The authors suggested that timely referral for HPN when patients have a higher functional status is the optimal time to offer the benefits of HPN and should be encouraged among healthcare professionals.

In a large, pan-European trial of 414 patients with incurable malignancy with no oral/enteral nutrition routes, Bozzetti et al. (51) found that KPS and Glasgow Prognostic Score were significant predictors of both 3- and 6-month survival ( $\mathrm{p}<0.001$ and $\mathrm{p}=0.001$ respectively). Tumour spread (locoregional, metastatic or both) was also found to be a significant predictor of survival ( $\mathrm{p}=0.008$ at 3 months and $<0.001$ at 6 months). Three- month survival ranged from $33 \%$ for patients with KPS $\leq 50$ and Glasgow Prognostic Score 2, to 79\% for patients with KPS $>$ 50, Glasgow Prognostic Score 0. No significant differences were found with regards to primary tumour site, age, BMI, weight loss or gender.

In the Madhok et al. (49) retrospective analysis, 7 patients with advanced ovarian cancer received HPN with higher World Health Organisation performance status $(\leq 1)$. Of these, 4 patients had short bowel syndrome and 3 patients had malignant intestinal obstruction. Median duration and survival were 8 months in both indications.

Conversely, Ruggeri et al. (38) conducted a prospective study where 333 patients with advanced malignancy received HPN (most frequently for intestinal obstruction). Mean KPS at outset was 51.35. After one month of HPN, KPS was reassessed. 40 patients deteriorated, 233 remained stable and 60 patients improved. Mean survival was significantly higher in patients with higher KPS ( $\mathrm{p}<0.001)$, though KPS values were not specified. The authors argued that HPN is futile, expensive, and would worsen quality of life in patients with a prognosis less than 6 weeks. 
In a study of 52 patients with advanced disease, Vashi et al. (52) observed an improvement in mean KPS from 60.1 at outset to 76.3 after 1 month of HPN $(\mathrm{p}=0.01)$ which was sustained at 2 and 3 months of HPN (73.2; $p=0.01$ and 78.7; $p=0.002)$. The authors reported that every month of HPN was associated with an improvement in KPS by 5.8 points ( $<<0.001) .27$ patients survived beyond 6 months and 12 patients survived $>1$ year. However, in this study, median survival for patients with KPS $\leq 50$ was higher than in patients with KPS > 50 (6.4 months versus 4.6 months; $\mathrm{p}=0.39$ ). The authors concluded that HPN can provide survival benefit, but that KPS $\leq 50$ was not associated with increased risk of death and therefore should not be used as an absolute predictor of HPN benefit.

This contrasted with the findings of Cotogni et al. (57) who examined nutritional status with survival. They found that patients assessed as 'well nourished' using the Subjective Global Assessment was positively predictive of survival $(\mathrm{p}<0.003)$ and those classified as 'severely malnourished' was a predictor of mortality $(\mathrm{p}<0.0001)$, with patients rated as poorly nourished having the lowest survival likelihood.

\section{Nutritional benefits of HPN}

$37.4 \%$ of patients in all studies had primary gastrointestinal tract malignancies. Santarpia et al. (44) found that patients with primary gastric cancer had significantly lower body weight ( $\mathrm{p}=$ $0.03)$ and BMI $(\mathrm{p}=0.03)$ than those with other primaries. Additionally, mean baseline KPS was 56 and lower KPS correlated with lower serum albumin (44).

Cotogni et al. (57) reported that $30 \%$ of patients with advanced malignancies who were 'malnourished' at baseline experienced an improvement in Subjective Global Assessment indices after 90 days of HPN. Bio-electrical Impedance Assessment scores improved after 30 days, but subsequently deteriorated. They also noted performance status improvements between baseline and 90 days (66.2\% of patients KPS $\geq 70$ at baseline and $77 \%$ after 90 days). Pelzer et al. (48) recruited 32 patients with advanced pancreatic cancer (stage IV, inoperable) and reduced nutritional status (marked cachexia with mean BMI of $19.7 \mathrm{~kg} / \mathrm{m}^{2}$ at baseline) who received HPN in addition to oral nutrition. They reported a modest improvement in mean BMI and Bio-electrical Impedance parameters with additional HPN support (p-value not estimated). Vashi et al. (52) found sustained significant improvements in Subjective Global Assessment indices ( $\mathrm{p}<0.05)$ at all measured time points, with a mean monthly improvement in weight of $1.3 \mathrm{~kg}(\mathrm{p}=0.009)$ from starting HPN. However, patients who were 'severely malnourished' (using Subjective Global Assessment) had a longer median survival than patients who were 'moderately malnourished' (3.2 versus 6.5 months respectively), perhaps due to small sample size, thereby limiting variation.

Senesse et al. (54) observed that patients' weights had increased by $2.7 \%$ ( $\mathrm{p}<0.001$ ) and $17.5 \%$ reached target weights after 28 days of HPN. In addition, serum albumin improved in 59\% of patients. They also noted a significant inverse relationship between performance status and serum albumin $(\mathrm{p}=0.032)$ and weight loss $(\mathrm{p}<0.001)$.

\section{Quality of Life}

Two studies examined the effect of HPN on quality of life in patients with advanced cancer, using the European Organisation for Research and Treatment of Cancer quality of life questionnaire (EORTC-QLQ-C30) validated questionnaire (27). Vashi et al. (52) found sustained significant monthly improvements in global quality of life by 6.3 points $(\mathrm{p}<0.001)$, physical functioning by 5.8 points $(\mathrm{p}=0.005)$, role of quality of life by 12.2 points $(\mathrm{p}<0.001)$, social quality of life by 6.2 points $(\mathrm{p}=0.04)$, fatigue by 9.1 points $(\mathrm{p}<0.001)$, nausea and vomiting by 7.1 points $(\mathrm{p}=0.005)$, insomnia by 6.5 points $(\mathrm{p}=0.02)$, appetite by 13.7 points $(\mathrm{p}<0.001)$, and constipation by 8.8 points $(\mathrm{p}<0.001)$. These improvements remained significant when controlling for age, gender, and treatment history. The greatest benefit, in 
terms of quality of life, was seen in patients who received 3 months of HPN, though significant improvements were also seen in patients who had HPN only for 1 or 2 months. The authors concluded that HPN had a sustained beneficial effect on quality of life in patients with advanced malignancy.

Cotogni et al. (55) surveyed 111 patients with stage III-IV metastatic cancers. All patients had some but insufficient oral nutritional intake (median intake: $500 \mathrm{kcal} /$ day). Univariate analysis revealed that global quality of life ( $\mathrm{p}<0.001)$, physical functioning $(\mathrm{p}<0.001)$, role functioning $(\mathrm{p}=0.007)$, emotional functioning $(\mathrm{p}<0.001)$, appetite loss $(\mathrm{p}=0.004)$ and fatigue $(\mathrm{p}=0.022)$ scores all had showed significant improvement over time after initiation of HPN. $44.1 \%$ of original respondents completed questionnaires after 4 months of HPN. A trend for global decline in quality of life was noted after 4 months of HPN, likely due to patients approaching death (median survival 4.7 months), however, this trend did not reach statistical significance. Of note, potential conflict of interest was disclosed due to the affiliation of the lead author with Baxter Healthcare.

The Rotterdam Symptom Checklist Questionnaire was used in 69 patients by Bozzetti et al. (41). They found that after one month of HPN, quality of life indices were stable rather than showing the expected progressive decline. Patients reported a high symptom(s) burden: asthenia (76\%), pain (35\%), oedema (14\%), dyspnoea (7\%). 80\% of the time spent on HPN was characterised by the presence of these symptoms. Despite reporting physical and psychological symptoms - anorexia, fatigue and feelings of worry or desperation, more than $50 \%$ of respondents answered "well" to the question, "how are you today?".

Senesse et al. (54) assessed the impact of HPN on quality of life using patient self-assessment questionnaires (Functional Assessment of Cancer Therapy-General) at inclusion and 28 days later. Questionnaire data was also collected from a proxy (most commonly a spouse in $70 \%$ of cases) and treating physician. Significant improvements were noted in global and physical quality of life scores; family impressions were also generally positive of HPN effect on global patient wellbeing. Of note the authors disclosed honoraria from Fresenius-Kabi and acknowledged assistance in preparation of the study manuscript.

Ruggeri et al. (38) linked quality of life to functional status (KPS), however did not use any validated measures to evaluate this.

\section{Complications}

Eight studies reported complication rates associated with $\operatorname{HPN}(38,46-48,50,54,56,57)$, most notably catheter related bloodstream infections (range $0.27-2.78$ episodes of CRBSI / 1000 catheter days). Two studies reported HPN / CVC related mortalities. In the study by Wang et al. (46), six patients (19\% of total study number) died from confirmed CRBSIs and they recorded a rate of $2.78 \mathrm{CRBSIs}$ per 1000 catheter days, which was considerably higher than other studies. Bozetti et al. (51) reported a 1.2\% HPN / CVC-associated mortality rate, though no further detail on cause of death was provided. Few studies provided detailed data on complications, however, rare events included CVC line failure, metabolic derangement, liver dysfunction, hyperglycaemia, venous thrombosis and bone pain $(43,45,47,50,52,54)$. Two studies reported microbiological culture results, of which the commonest causative pathogens were coagulase-negative Staphylococci and Candida (56). One study examining HPN and survival excluded patients who developed complications (45).

Severely malnourished patients and those with metastatic disease had almost double the risk of developing catheter related bloodstream infections than well-nourished patients without metastatic disease $(50,56)$. In addition, patients who survived longer were more likely to develop complications $(\mathrm{p}=0.046)$, due to increased risk of complications with longer duration of PN therapy (47). No anthropometric or nutritional parameters were significantly associated with the development of catheter related bloodstream infections. 
Interestingly, Senesse et al. (54) noted that adverse effects were more commonly reported by patients compared to their treating clinicians: with nausea, diarrhoea, and vomiting reported by $22 \%, 13 \%$ and $17 \%$ of patients respectively, versus $12 \%, 4 \%$ and $9 \%$ of clinicians.

\section{DISCUSSION}

This is the first study to review the literature on use of HPN in patients with advanced cancer for all indications, not only malignant bowel obstruction, in order to offer a wider understanding of current practice and highlight where further work is needed.

ESPEN guidelines recommend that PN/HPN can provide benefit in patients whose life expectancy exceeds 2 - 3 months $(12,13,58)$. Gold standard trial evidence, on HPN and survival in such patients is limited, and it would be both difficult and unethical to perform double blind, randomised control studies in this population, as this would involve depriving consenting patients of nutrition on a random basis. Data from hunger strikers shows that death from starvation in previously healthy adults occurs between 21 and 69 days without food (59). In patients with advanced cancer, this process is accelerated and occurs approximately twice as fast (60). Overall mean survival from this review was 7.3 months, however, it is difficult to extrapolate if HPN conferred any overall survival benefit due to confounding factors that are difficult to disentangle from HPN itself such as severity of disease. Cancer is heterogeneous; in patients with early, local, limited disease, nutritional requirements cannot be compared with those of a patient with advanced, metastatic disease and multi-organ involvement, who are likely to succumb to the disease process more quickly. Accurately predicting survival in this complex disease process remains difficult.

There was a general consensus that improved performance status is correlated with longer survival, with only two studies which examined this association in disagreement $(42,52)$. However, mean weight loss when starting HPN was $16.3 \%$ suggesting that patients are referred late in the cancer/cachexia trajectory. A number of authors suggest that in order to receive maximum benefit from HPN, patients should be referred earlier whilst performance status is higher and not merely when sarcopenia develops (5).

One study (44) found that cholinesterase, an enzyme needed for proper functioning of the nervous system and a prognostic factor for several cancers, was a significant predictor of survival, however, this was not borne out in any of the other studies. No other haematological or biochemical markers were significant in predicting survival benefit of HPN.

Definitions of advanced cancer were highly variable in the studies identified. A number of studies classified advanced or 'terminal' disease as 'incurable', 'irreversible', 'not responsive to further oncological treatment' or not having undergone treatment recently $(16,40,43,44$, $47,51,53,55)$, though numerous studies included patients still on single or combination oncological treatments $(16,52,54-57)$. Others included $2-3$ month life expectancy in their definition (42), or encompassed disease stage $\geq$ III/IV and / or the presence of metastatic disease $(39,45,47,49,54-57)$. Often, the terms 'advanced' and 'incurable' cancer were used synonymously to encompass the same group of patients. Wang et al. (46) noted that although all terminal cancer patients are oncologically 'incurable', not all incurable cancers are 'biologically terminal'. Thus, the heterogeneous definitions of advanced cancer, may also explain the large variability of survival data obtained (median 1.5-10.4 months) and to some extent may under-estimate the true proportion of 'advanced cancer' patients eligible for HPN. There was no clear overall consensus on the effect of HPN with nutritional indices in patients with advanced cancer and more work is needed to investigate this further.

The United Nations' Declaration of Human Rights (61) recognises the fundamental human right to food and it is essential to consider quality of life alongside survival benefit. In a study by Silvestri et al. only $22 \%$ of patients with advanced cancer stated they would choose 
palliative chemotherapy over supportive care alone, in order to benefit from the associated 3 month additional survival (62). Therefore, it is fundamental to establish the impact of HPN on quality of life in such patients, especially in those who are entirely PN-dependent for nutrition. There is a paucity of data in this area and quality of life was only measured in a few studies $(54,55,57)$, however, this did reveal some positive results. For example, Vashi et al. (52) showed significant and sustained improvements in a range of quality of life indices over 3 months follow up. Senesse et al. (54) found statistically significant improvements in global (P $=0.007)$ and physical $(\mathrm{P}<0.001)$ quality of life indices. The majority of the patients in this study received HPN for cancer-related malnutrition (89\%), cancer treatment-related complications (39\%), whilst only $7 \%$ of patients had intestinal failure. However, there was a high risk of study bias due to close involvement of a pharmaceutical company providing HPN services with the study. None of the studies reported negative effects of HPN on quality of life. Overall, HPN-related complication rates were low with catheter related bloodstream infections occurring most commonly (range $0.27-2.78$ per 1000 catheter days). $8 \mathrm{HPN} /$ central venous catheter-related mortalities $(0.23 \%)$ were reported and one study excluded participants who developed complications (45).

Clearly, there are important ethical, clinical, economic factors to be considered when initiating HPN therapy and patients and their caregivers must be included in this decision. At present, there are limited centres that are able to provide an HPN service, both nationally and internationally, however, HPN is increasingly prescribed for patients with advanced cancer. We found that there is heterogeneity of indications in the literature. This review finds that there is a sub-group of such patients who would benefit from timely initiation of HPN and that while the most frequent indication for HPN in advanced cancer is intestinal failure caused by malignant bowel obstruction, clinicians should be aware of other indications such as short bowel syndrome, fistulation, malabsoprtion and mucositis. Within the literature some studies have assessed the use of HPN in other non-intestinal failure indications such as cachexia, malnutrition, dysphagia and nausea / emesis. However, the benefit of such an approach is unclear.

In patients with advanced cancer and intestinal failure, we would recommend timely referral for nutritional support and discussion of HPN with patients and their caregivers. Further work is required to identify such patients more accurately and encourage earlier referral before worsening of performance status occurs. In parallel, further work is required to investigate the effect of HPN on quality of life, consideration of which is paramount in guiding decision making for this vulnerable cohort of patients.

\section{ACKNOWLEDGEMENTS}

This study did not receive any funding.

\section{FINANCIAL DISCLOSURE}

Pinal S. Patel is a research dietitian at UCLH and her research is funded by Calea. Konstantinos C. Fragkos is partially funded by a UCLH Marcel Levi Clinical Research Fellowship. These funders had no direct in influence in designing and reporting this study.

\section{CONFLICTS OF INTEREST}

None.

\section{AUTHOR CONTRIBUTIONS}

Simona Di Caro designed and supervised the study. Francis J. O'Hanlon, Lucia Fini, Konstantinos C. Fragkos, and Pinal S. Patel contributed to analysis and wrote the manuscript. 
O’Hanlon et al. 11

Simona Di Caro, Shameer J. Mehta, Farooq Rahman edited, wrote and supervised the preparation of the manuscript. 


\section{REFERENCES}

1 Bray F, Ferlay J, Soerjomataram I, Siegel RL, Torre LA, et al.: Global cancer statistics 2018: GLOBOCAN estimates of incidence and mortality worldwide for 36 cancers in 185 countries. CA Cancer J Clin 68, 394-424, 2018. doi: 10.3322/caac.21492

2 Siegel RL, Miller KD, Jemal A: Cancer statistics, 2018. CA Cancer J Clin 68, 7-30, 2018. doi: 10.3322/caac. 21442

3 Kim SH, Shin DW, Kim SY, Yang HK, Nam E, et al.: Terminal Versus Advanced Cancer: Do the General Population and Health Care Professionals Share a Common Language? Cancer Res Treat 48, 759-67, 2016. doi: 10.4143/crt.2015.124

4 Ryan AM, Power DG, Daly L, Cushen SJ, Ni Bhuachalla E, et al.: Cancer-associated malnutrition, cachexia and sarcopenia: the skeleton in the hospital closet 40 years later. Proc Nutr Soc 75, 199-211, 2016. doi: 10.1017/S002966511500419X

5 Baracos VE, Martin L, Korc M, Guttridge DC, Fearon KCH: Cancer-associated cachexia. Nat Rev Dis Primers 4, 17105, 2018. doi: 10.1038/nrdp.2017.105

6 Sadeghi M, Keshavarz-Fathi M, Baracos V, Arends J, Mahmoudi M, et al.: Cancer cachexia: Diagnosis, assessment, and treatment. Crit Rev Oncol Hematol 127, 91-104, 2018. doi: 10.1016/j.critrevonc.2018.05.006

7 Fearon K, Strasser F, Anker SD, Bosaeus I, Bruera E, et al.: Definition and classification of cancer cachexia: an international consensus. The Lancet Oncology 12, 489495, 2011. doi: 10.1016/s1470-2045(10)70218-7

8 Hopkinson JB, Wright DN, McDonald JW, Corner JL: The prevalence of concern about weight loss and change in eating habits in people with advanced cancer. J Pain Symptom Manage 32, 322-31, 2006. doi: 10.1016/j.jpainsymman.2006.05.012

9 Pironi L, Arends J, Baxter J, Bozzetti F, Pelaez RB, et al.: ESPEN endorsed recommendations. Definition and classification of intestinal failure in adults. Clin Nutr 34, 171-80, 2015. doi: 10.1016/j.clnu.2014.08.017

10 Pironi L, Arends J, Bozzetti F, Cuerda C, Gillanders L, et al.: ESPEN guidelines on chronic intestinal failure in adults. Clin Nutr 35, 247-307, 2016. doi: 10.1016/j.clnu.2016.01.020

11 Prado CM, Baracos VE, McCargar LJ, Reiman T, Mourtzakis M, et al.: Sarcopenia as a determinant of chemotherapy toxicity and time to tumor progression in metastatic breast cancer patients receiving capecitabine treatment. Clin Cancer Res 15, 2920-6, 2009. doi: 10.1158/1078-0432.CCR-08-2242

12 Arends J, Bachmann P, Baracos V, Barthelemy N, Bertz H, et al.: ESPEN guidelines on nutrition in cancer patients. Clinical Nutrition, 2016. doi: 10.1016/j.clnu.2016.07.015

13 Staun M, Pironi L, Bozzetti F, Baxter J, Forbes A, et al.: ESPEN Guidelines on Parenteral Nutrition: home parenteral nutrition (HPN) in adult patients. Clin Nutr 28, 467-79, 2009. doi: 10.1016/j.clnu.2009.04.001

14 Bakker H, Bozzetti F, Staun M, Leon-Sanz M, Hebuterne X, et al.: Home parenteral nutrition in adults: a european multicentre survey in 1997. ESPEN-Home Artificial Nutrition Working Group. Clin Nutr 18, 135-40, 1999. doi: 10.1054/clnu.1999.0021

15 British Artificial Nutrition Survey (BANS). BANS Report 2016: Artificial Nutrition Support in the UK 2005-2015, Adult Home Parenteral Nutrition \& Home Intravenous Fluids BAPEN (British Association of Parenteral and Enteral Nutrition): Worcestershire, 2016.

16 Keane N, Fragkos KC, Patel PS, Bertsch F, Mehta SJ, et al.: Performance Status, Prognostic Scoring, and Parenteral Nutrition Requirements Predict Survival in Patients with Advanced Cancer Receiving Home Parenteral Nutrition. Nutr Cancer 70, 73-82, 2018. doi: 10.1080/01635581.2018.1380206 
17 Arhip L, Garcia-Peris P, Romero RM, Frias L, Breton I, et al.: Direct costs of a home parenteral nutrition programme. Clin Nutr, 2018. doi: 10.1016/j.clnu.2018.06.972

18 Bozzetti F, Mori V: Nutritional support and tumour growth in humans: a narrative review of the literature. Clin Nutr 28, 226-30, 2009. doi: 10.1016/j.clnu.2009.02.006

19 Deshayes E, de Forges H, Fraisse J, Eberle MC, Guillemard S, et al.: Artificial nutrition in patients with cancer has no impact on tumour glucose metabolism: Results of the PETANC Study. Clin Nutr, 2018. doi: 10.1016/j.clnu.2018.08.033

20 Sowerbutts AM, Lal S, Sremanakova J, Clamp A, Todd C, et al.: Home parenteral nutrition for people with inoperable malignant bowel obstruction. Cochrane Database Syst Rev 8, CD012812, 2018. doi: 10.1002/14651858.CD012812.pub2

21 Moher D, Liberati A, Tetzlaff J, Altman DG, Group P: Preferred reporting items for systematic reviews and meta-analyses: the PRISMA statement. Ann Intern Med 151, 264-9, W64, 2009

22 Higgins JPT, Green S, Cochrane Collaboration. Cochrane handbook for systematic reviews of interventions. Chichester, England; Hoboken, NJ: Wiley-Blackwell, 2008.

23 Viswanathan M, Berkman ND: Development of the RTI item bank on risk of bias and precision of observational studies. $J$ Clin Epidemiol 65, 163-78, 2012. doi: 10.1016/j.jclinepi.2011.05.008

24 Douglas E, McMillan DC: Towards a simple objective framework for the investigation and treatment of cancer cachexia: the Glasgow Prognostic Score. Cancer Treat Rev 40, 68591, 2014. doi: 10.1016/j.ctrv.2013.11.007

25 Kelly CM, Shahrokni A: Moving beyond Karnofsky and ECOG Performance Status Assessments with New Technologies. J Oncol 2016, 6186543, 2016. doi: $10.1155 / 2016 / 6186543$

26 Peus D, Newcomb N, Hofer S: Appraisal of the Karnofsky Performance Status and proposal of a simple algorithmic system for its evaluation. BMC Med Inform Decis Mak 13, 72, 2013. doi: 10.1186/1472-6947-13-72

27 Fayers P, Bottomley A, Group EQoL, Quality of Life U: Quality of life research within the EORTC-the EORTC QLQ-C30. European Organisation for Research and Treatment of Cancer. Eur J Cancer 38 Suppl 4, S125-33, 2002

28 de Haes JC, van Knippenberg FC, Neijt JP: Measuring psychological and physical distress in cancer patients: structure and application of the Rotterdam Symptom Checklist. $\mathrm{Br}$ J Cancer 62, 1034-8, 1990

29 Fairclough DL, Cella DF: Functional Assessment of Cancer Therapy (FACT-G): nonresponse to individual questions. Qual Life Res 5, 321-9, 1996

30 Hozo SP, Djulbegovic B, Hozo I: Estimating the mean and variance from the median, range, and the size of a sample. BMC Med Res Methodol 5, 13, 2005. doi: 10.1186/1471-2288$5-13$

31 Wan X, Wang W, Liu J, Tong T: Estimating the sample mean and standard deviation from the sample size, median, range and/or interquartile range. BMC Med Res Methodol 14, 135, 2014. doi: 10.1186/1471-2288-14-135

32 Higgins JP, Thompson SG, Deeks JJ, Altman DG: Measuring inconsistency in metaanalyses. BMJ 327, 557-60, 2003. doi: 10.1136/bmj.327.7414.557

33 Bowden J, Tierney JF, Copas AJ, Burdett S: Quantifying, displaying and accounting for heterogeneity in the meta-analysis of RCTs using standard and generalised Q statistics. BMC Med Res Methodol 11, 41, 2011. doi: 10.1186/1471-2288-11-41

34 Fragkos KC, Tsagris M, Frangos CC: Publication Bias in Meta-Analysis: Confidence Intervals for Rosenthal's Fail-Safe Number. Int Sch Res Notices 2014, 825383, 2014. doi: $10.1155 / 2014 / 825383$ 
35 Huedo-Medina TB, Sanchez-Meca J, Marin-Martinez F, Botella J: Assessing heterogeneity in meta-analysis: Q statistic or I2 index? Psychol Methods 11, 193-206, 2006. doi: 10.1037/1082-989X.11.2.193

36 Higgins JP, Thompson SG: Quantifying heterogeneity in a meta-analysis. Stat Med 21, 1539-58, 2002. doi: 10.1002/sim.1186

37 Lundholm K, Daneryd P, Bosaeus I, Korner U, Lindholm E: Palliative nutritional intervention in addition to cyclooxygenase and erythropoietin treatment for patients with malignant disease: Effects on survival, metabolism, and function. Cancer 100, 1967-77, 2004. doi: $10.1002 /$ cncr.20160

38 Ruggeri E, Agostini F, Fettucciari L, Giannantonio M, Pironi L, et al.: Home artificial nutrition in advanced cancer patients. Tumori 99, 218-24, 2013. doi: 10.1700/1283.14195

39 Theilla M, Cohen J, Kagan I, Attal-Singer J, Lev S, et al.: Home parenteral nutrition for advanced cancer patients: Contributes to survival? Nutrition 54, 197-200, 2018. doi: 10.1016/j.nut.2017.03.005

40 Pasanisi F, Orban A, Scalfi L, Alfonsi L, Santarpia L, et al.: Predictors of survival in terminal-cancer patients with irreversible bowel obstruction receiving home parenteral nutrition. Nutrition 17, 581-584, 2001. doi: 10.1016/S0899-9007(01)00579-2

41 Bozzetti F, Cozzaglio L, Biganzoli E, Chiavenna G, De Cicco M, et al.: Quality of life and length of survival in advanced cancer patients on home parenteral nutrition. Clin Nutr 21, 281-8, 2002

42 Duerksen DR, Ting E, Thomson P, McCurdy K, Linscer J, et al.: Is there a role for TPN in terminally ill patients with bowel obstruction? Nutrition 20, 760-763, 2004. doi: 10.1016/j.nut.2004.05.010

43 Hoda D, Jatoi A, Burnes J, Loprinzi C, Kelly D: Should patients with advanced, incurable cancers ever be sent home with total parenteral nutrition? Cancer 103, 863-868, 2005. doi: 10.1002/cncr.20824

44 Santarpia L, Alfonsi L, Pasanisi F, De Caprio C, Scalfi L, et al.: Predictive factors of survival in patients with peritoneal carcinomatosis on home parenteral nutrition. Nutrition 22, 355-360, 2006. doi: 10.1016/j.nut.2005.06.011

45 Fan BG: Parenteral nutrition prolongs the survival of patients associated with malignant gastrointestinal obstruction. JPEN J Parenter Enteral Nutr 31, 508-10, 2007

46 Wang MY, Wu MH, Hsieh DY, Lin LJ, Lee PH, et al.: Home parenteral nutrition support in adults: experience of a medical center in Asia. JPEN J Parenter Enteral Nutr 31, 306-10, 2007. doi: 10.1177/0148607107031004306

47 Soo I, Gramlich L: Use of parenteral nutrition in patients with advanced cancer. Appl Physiol Nutr Metab 33, 102-6, 2008. doi: 10.1139/H07-152

48 Pelzer U, Arnold D, Govercin M, Stieler J, Doerken B, et al.: Parenteral nutrition support for patients with pancreatic cancer. Results of a phase II study. BMC Cancer 10, 86, 2010. doi: 10.1186/1471-2407-10-86

49 Madhok BM, Yeluri S, Haigh K, Burton A, Broadhead T, et al.: Parenteral nutrition for patients with advanced ovarian malignancy. J Hum Nutr Diet 24, 187-91, 2011. doi: 10.1111/j.1365-277X.2010.01127.x

50 Chermesh I, Mashiach T, Amit A, Haim N, Papier I, et al.: Home parenteral nutrition (HTPN) for incurable patients with cancer with gastrointestinal obstruction: do the benefits outweigh the risks? Med Oncol 28, 83-8, 2011. doi: 10.1007/s12032-010-9426-2

51 Bozzetti F, Santarpia L, Pironi L, Thul P, Klek S, et al.: The prognosis of incurable cachectic cancer patients on home parenteral nutrition: A multi-centre observational study with prospective follow-up of 414 patients. Annals of Oncology 25, 487-493, 2014. doi: 10.1093/annonc/mdt549 
52 Vashi PG, Dahlk S, Popiel B, Lammersfeld CA, Ireton-Jones C, et al.: A longitudinal study investigating quality of life and nutritional outcomes in advanced cancer patients receiving home parenteral nutrition. BMC Cancer 14, 593, 2014. doi: 10.1186/1471-2407-14593

53 Drissi M, Cwieluch O, Lechner P, Radziwill R, Vehling-Kaiser U, et al.: Nutrition care in patients with cancer: A retrospective multicenter analysis of current practice - Indications for further studies? Clin Nutr 34, 207-11, 2015. doi: 10.1016/j.clnu.2014.03.002

54 Senesse P, Tadmouri A, Culine S, Dufour PR, Seys P, et al.: A prospective observational study assessing home parenteral nutrition in patients with gastrointestinal cancer: benefits for quality of life. J Pain Symptom Manage 49, 183-191 e2, 2015. doi: 10.1016/j.jpainsymman.2014.05.016

55 Cotogni P, De Carli L, Passera R, Amerio ML, Agnello E, et al.: Longitudinal study of quality of life in advanced cancer patients on home parenteral nutrition. Cancer Med 6, 17991806, 2017. doi: 10.1002/cam4.1111

56 Vashi PG, Virginkar N, Popiel B, Edwin P, Gupta D: Incidence of and factors associated with catheter-related bloodstream infection in patients with advanced solid tumors on home parenteral nutrition managed using a standardized catheter care protocol. BMC Infect Dis 17, 372, 2017. doi: 10.1186/s12879-017-2469-7

57 Cotogni P, Monge T, Fadda M, De Francesco A: Bioelectrical impedance analysis for monitoring cancer patients receiving chemotherapy and home parenteral nutrition. BMC Cancer 18, 990, 2018. doi: 10.1186/s12885-018-4904-6

58 Bozzetti F, Arends J, Lundholm K, Micklewright A, Zurcher G, et al.: ESPEN Guidelines on Parenteral Nutrition: non-surgical oncology. Clin Nutr 28, 445-54, 2009. doi: 10.1016/j.clnu.2009.04.011

59 Arnold F: Clinical care of hunger strikers. Lancet 372, 1544, 2008. doi: 10.1016/S01406736(08)61650-5

60 August DA, Thorn D, Fisher RL, Welchek CM: Home Parenteral Nutrition for Patients with Inoperable Malignant Bowel Obstruction. Journal of Parenteral and Enteral Nutrition 15, 323-327, 1991. doi: 10.1177/0148607191015003323

61 UN General Assembly: Universal declaration of human rights. 1948

62 Silvestri G, Pritchard R, Welch HG: Preferences for chemotherapy in patients with advanced non-small cell lung cancer: descriptive study based on scripted interviews. BMJ 317, 771-5, 1998 


\section{FIGURE AND TABLES}

Figure 1. Flow chart of studies.

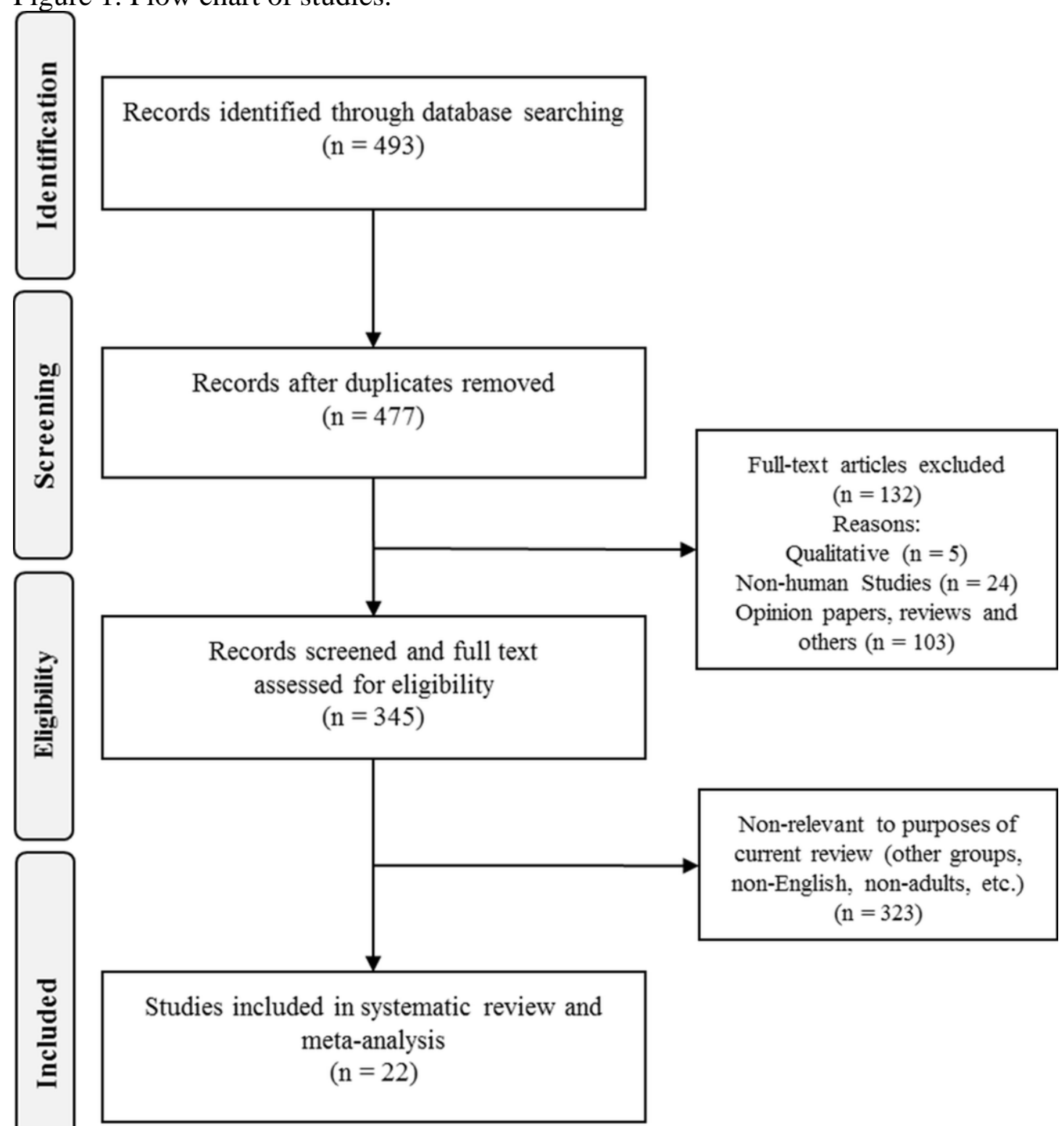


Figure 2. Quality Assessment of Studies.

Incomplete Outcome Data (attrition bias)

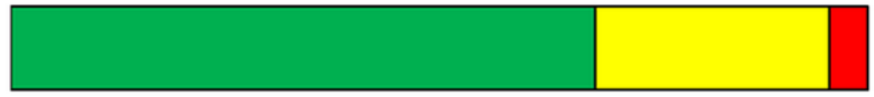

Selective Reporting (reporting bias)

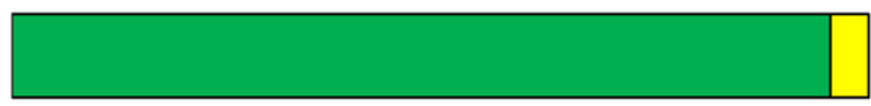

Confounding Factors analysed

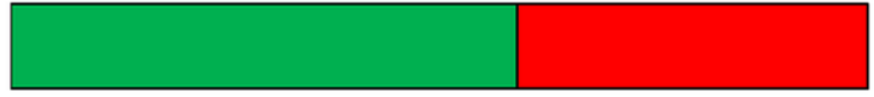

Balanced Groups (Confounding)

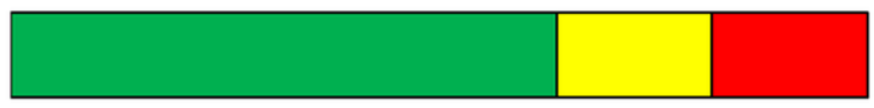

Eligibility Criteria (Selection bias)

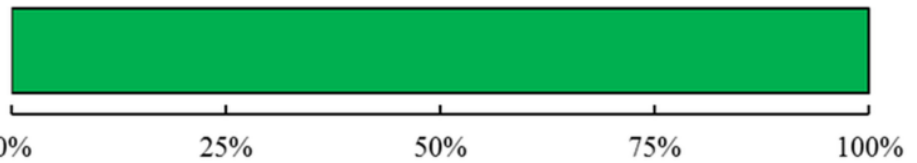

口Low Risk of Bias aUnclear Risk of Bias $\quad$ aHigh Risk of Bias 
Figure 3. Forest plots. A. BMI, B. Percentage of weight loss, C. KPS, D: Survival (months), E: HPN duration (months).

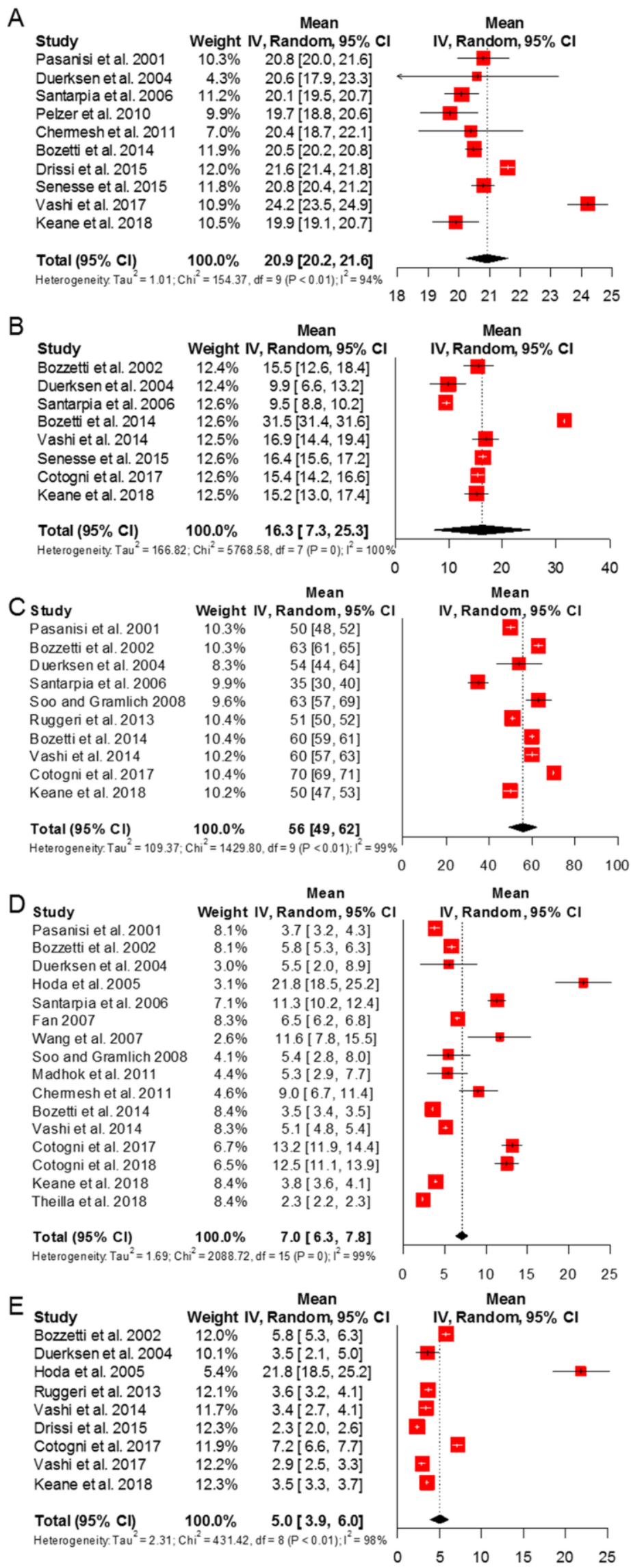


Table 1. Description of performance status and prognostic scores definition

\author{
Prognostic scoring \\ Glasgow Prognostic Score (24) \\ - Framework for the assessment and treatment of cancer cachexia \\ - Score 2: C-Reactive Protein $>10 \mathrm{mg} / \mathrm{L}$ and Albumin $<35 \mathrm{~g} / \mathrm{L}$ \\ - Score 1: C-Reactive Protein $>10 \mathrm{mg} / \mathrm{L}$ or Albumin $<35 \mathrm{~g} / \mathrm{L}$ \\ - Score 0: C-Reactive Protein $\leq 10 \mathrm{mg} / \mathrm{L}$ or Albumin $\geq 35 \mathrm{~g} / \mathrm{L}$
}

\title{
Performance Status
}

The Eastern Cooperative Oncology Group Scale of Performance Status (also referred to as World Health Organization performance status) (25)

- Describes a patient's level of functioning in terms of their ability to care for themselves, daily activity, and physical ability (walking, working, etc.)

- Commonly used as a prognostic tool, as a selection criterion for cancer research, and to help guide treatment

- Scores range from 0 (Fully active, able to carry on all pre-disease performance without restriction) to 5 (Death)

Karnofsky Performance Status (26)

- Provides a standardised tool for assessing patients' ability to perform ordinary tasks

- Scores are allocated in increments of 10 and range from 0 to $100 \%$.

- A reduced score indicates that the patient requires greater assistance to perform tasks

\section{Quality of Life}

EORTC QLQ-C30 (27)

- 30-item validated tool for assessing health related quality of life of cancer patients

- Five functional scales (physical, role, cognitive, emotional, and social)

- Three symptom scales (fatigue, pain, and nausea and vomiting)

- Global health status/quality of life scale

- Single items assessing additional symptoms commonly reported by cancer patients (dyspnoea, loss of appetite, insomnia, constipation and diarrhoea)

- Perceived financial impact of the disease

Rotterdam Symptom Checklist (28)

- 39-item generic cancer questionnaire

- Grouped in four scales (score 0-100): physical symptoms, psychological symptoms, daily life activities, and overall quality of life

- It provides a score for each scale and subscale (fatigue, pain, gastrointestinal, and chemotherapy)

- High scores represent a worse quality of life, except for activity, which is inversely interpreted

Functional Assessment of Cancer Therapy-General questionnaire (29)

- health-related quality of life assessment tool for patients undergoing cancer therapy

- four subscales: physical, social/family, emotional and functional well-being

- Questions: 5-point rating scale ( $0=$ not at all; 4 = very much)

- Total score is computed as sum of four subscale scores (range 0-108 points)

- Negatively worded items are reverse-scored prior to summing so that higher subscale and total scores indicate better quality of life 
Table 2. Studies included in the systematic review.

\begin{tabular}{|c|c|c|c|c|c|c|c|}
\hline Study & Design & country & Endpoint(s) & $\mathbf{N}$ & Type of Malignancy & $\begin{array}{l}\text { Main indication } \\
\text { for TPN }\end{array}$ & $\begin{array}{l}\text { Expected } \\
\text { Prognosis } \\
\end{array}$ \\
\hline $\begin{array}{l}\text { Pasanisi } \\
\text { et al. (40) }\end{array}$ & Retrospective & Italy & Survival & 76 & $\begin{array}{l}\text { Gynaecological, } \\
\text { Gastrointestinal }\end{array}$ & $\begin{array}{l}\text { Bowel } \\
\text { Obstruction }\end{array}$ & Any \\
\hline $\begin{array}{l}\text { Bozzetti } \\
\text { et al. (41) }\end{array}$ & Prospective & Italy & $\begin{array}{l}\text { Survival, Quality of } \\
\text { Life }\end{array}$ & 69 & $\begin{array}{l}\text { Gastrointestinal, } \\
\text { Gynaecological, Breast, } \\
\text { Other }\end{array}$ & $\begin{array}{l}\text { Bowel } \\
\text { Obstruction }\end{array}$ & Not reported \\
\hline $\begin{array}{l}\text { Lundhol } \\
\text { m et al. } \\
(37) \\
\end{array}$ & Prospective & Sweden & $\begin{array}{l}\text { Survival, Nutritional } \\
\text { Status }\end{array}$ & 134 & Solid tumours & Cancer Cachexia & Over 6 months \\
\hline $\begin{array}{l}\text { Duerksen } \\
\text { et al. (42) }\end{array}$ & Retrospective & Canada & Survival & 9 & $\begin{array}{l}\text { Gastrointestinal } \\
\text { (metastatic) }\end{array}$ & $\begin{array}{l}\text { Bowel } \\
\text { Obstruction }\end{array}$ & Over 2 months \\
\hline $\begin{array}{l}\text { Hoda et } \\
\text { al. (43) }\end{array}$ & Retrospective & USA & Survival & 52 & $\begin{array}{l}\text { Gastrointestinal, } \\
\text { Gynaecological, Other }\end{array}$ & metastasis & Not reported \\
\hline $\begin{array}{l}\text { Santarpia } \\
\text { et al. (44) }\end{array}$ & Retrospective & Italy & $\begin{array}{l}\text { Survival, Quality of } \\
\text { Life, Nutritional } \\
\text { Status }\end{array}$ & 152 & $\begin{array}{l}\text { Gastrointestinal, } \\
\text { Gynaecological, Breast, } \\
\text { Other }\end{array}$ & $\begin{array}{l}\text { Bowel } \\
\text { Obstruction }\end{array}$ & Any \\
\hline Fan (45) & Retrospective & China & Survival & 115 & Gastrointestinal & Cancer Cachexia & Few months \\
\hline $\begin{array}{l}\text { Wang et } \\
\text { al. (46) }\end{array}$ & Retrospective & Taiwan & Survival & 20 & $\begin{array}{l}\text { Gynaecological, } \\
\text { Gastrointestinal, Lung }\end{array}$ & Cancer Cachexia & Few months \\
\hline $\begin{array}{l}\text { Soo and } \\
\text { Gramlich } \\
(47)\end{array}$ & Retrospective & Canada & Survival & 38 & $\begin{array}{l}\text { Gynaecological, } \\
\text { Gastrointestinal, } \\
\text { Haematological }\end{array}$ & Cancer Cachexia & Few months \\
\hline $\begin{array}{l}\text { Pelzel } \\
(48)\end{array}$ & Prospective & $\begin{array}{l}\text { German } \\
\mathrm{y}\end{array}$ & Nutritional Status & 32 & Pancreas & $\begin{array}{l}\text { Bowel } \\
\text { Obstruction }\end{array}$ & Not reported \\
\hline $\begin{array}{l}\text { Madhok } \\
\text { et al. (49) }\end{array}$ & Retrospective & UK & Survival & 7 & Advanced Ovarian Cancer & Cancer Cachexia & Few months \\
\hline $\begin{array}{l}\text { Chermes } \\
\text { h et al. } \\
(50)\end{array}$ & Prospective & Israel & Survival & 28 & $\begin{array}{l}\text { Gastrointestinal, } \\
\text { Gynaecological, Larynx, } \\
\text { Breast }\end{array}$ & $\begin{array}{l}\text { Bowel } \\
\text { Obstruction }\end{array}$ & Not Reported \\
\hline $\begin{array}{l}\text { Ruggeri } \\
\text { et al. (38) }\end{array}$ & Retrospective & Italy & $\begin{array}{l}\text { Survival, Quality of } \\
\text { Life }\end{array}$ & 333 & $\begin{array}{l}\text { Head \& Neck, } \\
\text { Gastrointestinal, } \\
\text { Gynaecological, Other }\end{array}$ & Cancer Cachexia & $\begin{array}{l}\text { Over } 1.5 \\
\text { months }\end{array}$ \\
\hline $\begin{array}{l}\text { Bozetti et } \\
\text { al. (51) }\end{array}$ & Prospective & $\begin{array}{l}\mathrm{EU} \\
\text { countrie } \\
\mathrm{S}\end{array}$ & Survival & 414 & $\begin{array}{l}\text { Head \& Neck, } \\
\text { Gastrointestinal, } \\
\text { Gynaecological }\end{array}$ & $\begin{array}{l}\text { Bowel } \\
\text { Obstruction }\end{array}$ & Over 3 months \\
\hline $\begin{array}{l}\text { Vashi et } \\
\text { al. (52) }\end{array}$ & Prospective & USA & $\begin{array}{l}\text { Quality of Life, } \\
\text { Nutritional Status }\end{array}$ & 52 & $\begin{array}{l}\text { Gastrointestinal, } \\
\text { Gynaecological, Other }\end{array}$ & Cancer Cachexia & Over 3 months \\
\hline $\begin{array}{l}\text { Drissi et } \\
\text { al. }(53)\end{array}$ & Retrospective & $\begin{array}{l}\text { German } \\
\mathrm{y}\end{array}$ & Nutritional Status & 1137 & $\begin{array}{l}\text { Gastrointestinal, } \\
\text { Gynaecological, Breast, } \\
\text { Other }\end{array}$ & Cancer Cachexia & Not Reported \\
\hline $\begin{array}{l}\text { Senesse } \\
\text { et al. (54) }\end{array}$ & Prospective & France & $\begin{array}{l}\text { Quality of Life, } \\
\text { Nutritional Status }\end{array}$ & 370 & Gastrointestinal & Cancer Cachexia & Any \\
\hline $\begin{array}{l}\text { Cotogni } \\
\text { et al. (55) }\end{array}$ & Prospective & Italy & $\begin{array}{l}\text { Survival, Quality of } \\
\text { Life }\end{array}$ & 111 & Gastrointestinal, Other & $\begin{array}{l}\text { Bowel } \\
\text { Obstruction }\end{array}$ & Over 2 months \\
\hline $\begin{array}{l}\text { Vashi et } \\
\text { al. (56) }\end{array}$ & Retrospective & USA & $\begin{array}{l}\text { Catheter Related } \\
\text { Sepsis }\end{array}$ & 335 & $\begin{array}{l}\text { Gastrointestinal, } \\
\text { Gynaecological, Other }\end{array}$ & Cancer Cachexia & Not Reported \\
\hline $\begin{array}{l}\text { Cotogni } \\
\text { et al. (57) }\end{array}$ & Prospective & Italy & $\begin{array}{l}\text { Survival, Nutritional } \\
\text { Status }\end{array}$ & 65 & Gastrointestinal, Other & $\begin{array}{l}\text { Bowel } \\
\text { Obstruction }\end{array}$ & Over 2 months \\
\hline $\begin{array}{l}\text { Keane et } \\
\text { al. (16) }\end{array}$ & Retrospective & UK & $\begin{array}{l}\text { Survival, Nutritional } \\
\text { Status }\end{array}$ & 107 & $\begin{array}{l}\text { Gastrointestinal, } \\
\text { Gynaecological, Breast, } \\
\text { Other }\end{array}$ & $\begin{array}{l}\text { Bowel } \\
\text { Obstruction }\end{array}$ & Over 3 months \\
\hline $\begin{array}{l}\text { Theilla et } \\
\text { al. (39) }\end{array}$ & Retrospective & Israel & Survival & 153 & Gastrointestinal, Other & Cancer & Not Reported \\
\hline
\end{tabular}

